\title{
Especialidades Médicas: Estudo Psicossocial
}

\author{
Maria Luiza De Mattos Fiore ${ }^{1}$ \\ Latife Yarigi \\ Universidade Federal de São Paulo
}

\begin{abstract}
Resumo
Estudo exploratório sobre fatores psicológicos e sociais envolvidos na escolha e prática das diversas especialidades médicas, com base na formulação sociológica de Bourdieu e nas considerações de Dejours a respeito do encontro do homem com seu trabalho. O estudo é baseado na análise de conteúdo de entrevistas livres, seguidas de questionário de levantamento social aplicados em 40 médicos atuantes, de ambos os sexos, de diferentes faixas etárias e várias especialidades na cidade de São Paulo. O exame, em profundidade, das entrevistas revela que: a) os conflitos psicológicos inerentes à formação da identidade médica e a sua prática são influenciados por aspectos sócio-econômicos interiorizados e decorrentes do estrato social de origem do médico; b) as experiências vividas e influenciadas pelo estrato sócio-econômico de origem de cada indivíduo determinaram a organização e a complexidade do espaço subjetivo e, portanto, de suas percepções e de seu comportamento prático; e, c) a hierarquia de valores na Medicina pode ser considerada como defesa coletiva contra ansiedades resultantes da tarefa médica e do constante lidar com situações de impotência.

Palavras-chave: Abordagem psicossocial; especialidades médicas; identidade médica.
\end{abstract}

Medical Specialisations: A Psychosocial Study

\begin{abstract}
This paper presents an exploratory study of the psychological and social factors related to the choice and practice of the various medical specialities, based on the sociological formulation of Bourdieu and the considerations of Dejours concerning man's encounter with his work. The study was based on the analysis of an open interview and social survey questionnaire applied on 40 active medical doctors of both sexes, different ages, and several specialities, in the city of Sao Paulo, Brazil. The results of a thorough analysis of the interviews reveals that: a) the psychological conflicts inherent in the formation of a medical identity and the practice of medicine are influenced by acquired socio-economic elements that lead to differing practical solutions and results depending on social class descent; b) the experiences of each individual, according to his/her socio-economic status, determine the organisation and complexity of his/her subjective space and, therefore, of his/her perceptions and practical behaviour; c) the hierarchy of values in Medicine can be considered as a collective defence against anxieties resulting from medical tasks and the constant dealing with situations of powerlessness.

Keywords: Psychosocial approach; medical specialities;medical identity.
\end{abstract}

As diferentes percepções e abordagens adotadas pelos médicos de distintas especialidades e observadas na prática da interconsulta médico-psicológica nos levaram a perguntar como e por que elas se originam e se distribuem no campo de trabalho médico.

A fim de compreender a mediação entre indivíduo e sociedade, utilizamos a teoria da prática de Bourdieu $(1987,1996)$ articulada aos conceitos de Dejours (1992) e Dejours, Abdoucheli e Jayet (1994) acerca do indivíduo e sua relação com o trabalho. As experiências vividas e conhecidas pelo indivíduo, bem como o grau de complexidade dessas experiências, determinam a organização e complexidade do espaço psicológico e, conseqüentemente, as práticas e as representações desses indivíduos (Rodrigues, 1978).

No presente trabalho, o campo médico foi considerado como um espaço de poder onde as pessoas que nele concorrem ocupam diferentes posições, de acordo com a distribuição desigual de bens materiais e simbólicos. Cada agente social atua dentro de uma faixa de possibilidades distintas quanto à visão de mundo e de representações profissionais (Bourdieu, 1996). O campo médico foi também entendido como um 'teatro' onde são transpostas as questões permeadas pelo sofrimento da história pessoal de cada um (Dejours, 1992).

\footnotetext{
1 Endereço para correspondência: Rua Botucatu, 740, 04023 900, São Paulo, SP. Fone: (11) 5702828; Fax: (11) 55717254. E-mail: marialuiza_fiore@yahoo.com; lyazigi@aclnet.com.br
}

\section{Método}

Os participantes foram 40 médicos, renomados, com reconhecimento nos meios médico e social, de diferentes especialidades e em atividade na cidade de São Paulo. Para identificar os profissionais renomados ou bem-sucedidos na profissão que iriam compor o grupo, 'informantes chaves' foram consultados. Patton (1990) chama de snowball or chain sampling o procedimento de buscar, por meio de pessoas atuantes na área, 'informantes chaves', indicações de indivíduos a serem inclúdos no estudo. Assim, quatro a cinco pessoas de cada especialidade médica foi solicitada a oferecer nomes de profissionais de ambos os sexos de destaque em sua área. As pessoas mais freqüentemente mencionadas foram incluídas no grupo de participantes.

Os instrumentos utilizados foram: a) entrevista livre em que era solicitado à pessoa que falasse de sua vida - o objetivo era permitir uma produção espontânea, em que os temas e sua seqüência seguissem os determinantes internos; b) questionário psicossocial (Rodrigues,1978) com o intuito de traçar a trajetória social da família e da pessoa. Foram feitas perguntas específicas sobre a escolaridade e profissão dos avós, pais, irmãos e cônjuges, quando casados, bem como perguntas abertas a respeito da escolha da profissão de médico e da especialidade, buscando complementar os dados da entrevista livre. 
Todo o material produzido, entrevistas e questionários, coletado por uma das autoras, foi gravado e posteriormente transcrito na íntegra. Em seguida, os dados foram submetidos à análise de conteúdo de acordo com a proposta de Bardin (1977), ou seja, sem caracterizações pré-estabelecidas. Assim, várias leituras do material foram realizadas até que afluíssem impressões que orientassem a existência de determinadas categorias de análise. Essas categorias, inicialmente provisórias, seriam ou não confirmadas por meio da releitura das entrevistas.

\section{Resultados}

\section{Participantes}

Dos 40 participantes, 19 são mulheres e 21 homens, médicos formados nas décadas de 1940, 50, 60 e 70. A maioria estava casada, $90 \%$ dos homens e $68 \%$ das mulheres, sendo que $62,5 \%$ continuava ligado às faculdades de Medicina (Ver Tabela 1).

Tabela 1

Distribuição quanto à Idade e Sexo

\begin{tabular}{cccc}
\hline Idade/sexo & Masculino & Feminino & Total \\
\hline$>70 \mathrm{a}$ & 02 & 01 & 03 \\
$69-60 \mathrm{a}$ & 01 & 05 & 06 \\
$59-50 \mathrm{a}$ & 07 & 04 & 11 \\
$49-40 \mathrm{a}$ & 11 & 09 & 20 \\
\hline Total & 21 & 19 & 40 \\
\hline
\end{tabular}

\section{Escolha da Medicina}

Origens

A profissão é produto do trabalho social de construção de um grupo e de uma representação dos grupos. O espaço social possibilita a construção de classes teóricas tão homogêneas quanto possível. A classe social é constituída por um conjunto de agentes que ocupam posições semelhantes e, portanto, apresentam práticas, representações e classificações semelhantes. Os inter-relacionamentos, numa determinada posição, acabam por dotar o indivíduo de um habitus, que pode ser definido como esquemas adquiridos pela prática e que se organizam em categorias de percepção, apreciação e classificação inconscientes. Esses princípios são vários e dependem do lugar e momento. A 'trajetória social' corresponde a estas diversas posições de um indivíduo em uma determinada estrutura, em períodos diferentes (Bourdieu, 1987).

Para Bourdieu (1987), as diferentes classes sociais organizam-se em torno de três posições básicas: a) classe popular, relacionada com as profissões manuais agrícolas, operários e pequenos comerciantes; b) classe média, referente a funcionários, empresários industriais de porte médio, comerciantes, técnicos e dirigentes de nível médio; c) classe superior, relativa a grandes administradores, diretores e membros das profissões liberais.

No momento do estudo, todos os representantes de nossa amostra se incluíam na posição superior. Entretanto, cada um deles, no decorrer de sua vida, ocupara diferentes posições, de acordo com fatores ligados a sexo, idade e a história de vida, esta vinculada à história familiar que se remete à história da classe social da família (Ver a Tabela 2).

Tabela 2

Distribuição quanto à Classe Social e Sexo

\begin{tabular}{lccc}
\hline Classe/sexo & Masculino & Feminino & Total \\
\hline Popular & 03 & 05 & 08 \\
Média & 08 & 10 & 18 \\
Superior & 10 & 04 & 14 \\
\hline Total & 21 & 19 & 40 \\
\hline
\end{tabular}

Observa-se que $35 \%$ da amostra são provenientes da classe social superior, $45 \%$ da classe média e $20 \%$ da classe popular. Desta forma, esse grupo de médicos é originário predominantemente da camada social superior. Cabe conhecer como se deu a entrada de cada participante no campo profissional.

As estruturas mentais são, também, produto da incorporação das estruturas sociais. Os 'agentes' são distribuídos em função de sua 'posição' ou 'classe' de acordo com seu 'capital'. O 'capital' possui dois princípios de diferenciação: o 'econômico' e o 'simbólico'. Por exemplo, são portadores de grande volume de capital empresários e professores universitários. No entanto, do ponto de vista da estrutura do capital, os empresários possuem capital econômico maior do que cultural, enquanto que no caso dos professores se dá o contrário. As heranças culturais e as estratégias familiares para a ascensão social são determinantes na avaliação do capital simbólico (Bourdieu,1987).

A maioria $(82,5 \%)$ de nossos entrevistados tem pelo menos um avô estrangeiro, sendo 45\% imigrantes ou com um dos pais imigrante. Destacam-se as origens italiana (15), portuguesa (7), espanhola (4), judaica (4), japonesa (4) e um representante de cada das seguintes origens: libanesa, armênia, húngara, alemã e chinesa.

\section{Estratégias familiares}

A ascendência estrangeira dos 'agentes' modifica, muitas vezes, a estrutura do capital total. Por exemplo, enquanto algumas pessoas mudam de país para tentar novas oportunidades de vida, outras foram obrigadas a fugir de perseguições e trazem consigo um capital cultural sem relação de igualdade com o econômico. Isso implica uma variabilidade cultural que é refletida na ocupação, hábitos e, principalmente, na estratégia familiar de cada um.

Rodrigues (1981) observa que a distribuição de privilégios em uma familia depende de sua visão de mundo, do tipo de interação que mantém com o meio ambiente e das estratégias de sobrevivência e de reprodução típicas de uma determinada classe social. Algumas vezes, os papéis que o indivíduo assume são conseqüência de atribuições feitas pelo grupo familiar em função de uma avaliação consensual de seu desempenho. Isto não significa que o indivíduo obrigatoriamente desempenhe esse papel, mas existe uma possibilidade maior de que isso aconteça. Assim, em nosso grupo, observamos grande predominância de primogênitos (12 homens e 10 mulheres), principalmente das classes média $(55,5 \%)$ e superior $(64,3 \%)$. 
Os pais projetam no filho seus sonhos de desejo não realizados. Cada criança é portadora da missão de assegurar a continuidade narcísica de sua família.

Meu pai tinha, entre uma das vontades dele, a de estudar Medicina. Coisa que ele não conseguiu fazer. Ele terminou o curso colegial e, em 33, ele fugiu da Alemanha. (primogênito, classe média de origem judaica)

A distribuição de privilégios pressupõe um jogo contínuo de projeções e introjeções desde o nascimento. O diploma como estratégia familiar de ascensão social é mais evidente nas famílias de imigrantes. Em geral, o ganho de capital econômico é tarefa principal dos que emigraram e o ganho de reputação e prestígio, capital simbólico, fica a cargo dos filhos e netos.

\section{Experiências pessoais}

A identidade ocupacional desenvolve-se integrada à identidade pessoal em sentido amplo. A ocupação define-se ao longo do tempo na interação do indivíduo em um determinado contexto históricosocial. Deste modo, não existe ocupação médica abstrata e sim pessoas com várias práticas médicas diferentes: pediatra, psiquiatra, neurocirurgião e outras (Bohoslavsky,1991).

Em nossas entrevistas, ficou clara a presença do poder e do prestígio na representação social do médico. Observamos que esta tem particularidades que variam de acordo com a classe social de origem. Assim, na classe popular, o relacionamento médico-paciente está revestido da admiração a uma figura distante e do poder econômico.

$\mathrm{Na}$ minha família não tem nenhum médico, mas eu era garoto de ginásio e quando eu ia para o colégio eu passava pelo famoso Instituto de Otorrino ... eu também estive lá como paciente e via aquele movimento, me impressionou ... naquela época, eu me lembro muito bem que os médicos viviam muito bem. Eles tinham um padrão muito bom. (classe popular)

Entre os entrevistados com origem na classe média, são salientados valores universais.

Com 14, 15 anos todo mundo é idealista. Então, eu tinha uma porção de visões idealistas, assim de poder melhorar o mundo e, é claro que a primeira coisa é que quem mais parece que melhora o mundo é o médico. (classe média)

$\mathrm{Na}$ classe social superior o prestígio, aparece com o interesse pela manutenção do poder e perpetuação do status quo: Tenho 49 anos. E eu sou primeiro filho, de um pai médico, que também é filho de médico e uma mãe jovem (classe alta).

Sabe-se que, quanto maior o capital cultural da familia, maior será a educação escolar oferecida a seus filhos. A educação escolar atinge sua maior eficácia na medida em que é exercida em indivíduos já dotados pela educação familiar. O capital cultural não corresponde ao capital econômico. Assim, o mercado escolar possui uma autonomia relativa que justifica a 'ideologia do mérito escolar'. Os estudantes da classe popular sofrem seleção maior do que os provenientes da classe alta, só os que são realmente inteligentes e talentosos conseguem superar as barreiras sociais (Bourdieu \& Passeron, 1982).

A preocupação de ascensão social está presente em todas as entrevistas dos representantes de familias originárias da classe popular e média, assim como em três entrevistados incluídos no grupo proveniente da classe superior. Neste segmento, a ascensão se evidencia com a escolha de uma profissão de maior prestígio do que a do pai.

Eu venho de uma família de comerciantes. Meu pai era comerciante. E sempre há aquela perspectiva de que a próxima geração faça algo; o meu irmão, que tem 6 anos de diferença comigo, optou pela Engenharia. E eram as possibilidades que se abriam: engenheiro, médico ou advogado. Em casa sempre tinha essa idéia de engenheiro ou médico, advogado nunca era uma profissão valorizada. (filho caçula de imigrantes judeus da Europa Central)

Nos últimos 20 anos, o acesso das mulheres a faculdades de Medicina tornou-se cada vez mais freqüente. Mas, em diversos casos, é comum o relato de resistências impostas às mulheres por sua família ao estudo da Medicina em todas as classes sociais.

No terceiro ano, era a idéia de eu estudar em São Paulo, porque eu já queria fazer Medicina e o meu pai incentivava muito. Meu pai era uma pessoa culta e numa época em que as mulheres quase não estudavam, não faziam curso superior. Minha mãe era de opinião de que a gente devia se preparar para a família. Então, eu fiz curso de bordado, curso de piano, tudo que as moças da época faziam. (filha de italiano, formada em 1951)

\section{Opção pela Especialidade}

\section{Capital simbólico}

Uma das etapas da busca de destaque, de distinção, é a escolha da especialidade médica. Neste trabalho, as especialidades dos participantes foram reunidas em quatro grupos, de acordo com os diferentes tipos de relacionamento médico-paciente: clínicos, cirurgiões, medicina preventiva e métodos diagnósticos. Os clínicos, com intenso relacionamento médico-paciente, foram subdivididos em dois grupos - psiquiatras e não-psiquiatras - por causa das características de seus pacientes e das tarefas envolvidas. Os cirurgiões, com menor período de relacionamento médico-paciente, adotam condutas altamente técnicas e pragmáticas. O grupo de métodos diagnósticos, com quase nenhum relacionamento médico-paciente, desenvolve trabalho de elucidação diagnóstica ou de tratamento específico, como no caso da Radioterapia. Os representantes da Medicina Preventiva dedicam-se a programas de pesquisa relacionados à Saúde Pública, cujo foco é a comunidade.

A distribuição dos grupos de especialidades, em relação às classes sociais de origem, encontra-se no Tabela 3.

O capital simbólico de cada participante foi identificado pela linguagem e pelas formas de expressão empregadas durante a entrevista, além da informação obtida pelo conteúdo explícito, tais como cursos paralelos à universidade, formas de lazer e outros interesses não-profissionais, conforme proposta de Bourdieu (1996). 
Tabela 3

Distribuição das Especialidades e Classe Social de Origem

\begin{tabular}{|c|c|c|c|c|c|c|c|c|}
\hline \multirow{2}{*}{$\begin{array}{l}\text { Especialidades/ } \\
\text { Classe social de origem }\end{array}$} & \multicolumn{2}{|c|}{ Classe popular } & \multicolumn{2}{|c|}{ Classe média } & \multicolumn{2}{|c|}{ Classe superior } & \multicolumn{2}{|c|}{ Total } \\
\hline & Homem & Mulher & Homem & Mulher & Homem & Mulher & Homem & Mulher \\
\hline Clínicas & 2 & 2 & 3 & 3 & 1 & 1 & 6 & 6 \\
\hline Psiquiátrica & 0 & 0 & 0 & 2 & 3 & 0 & 3 & 2 \\
\hline Cirúrgicas & 1 & 2 & 3 & 3 & 3 & 2 & 7 & 7 \\
\hline Mét. diag. & 0 & 1 & 1 & 2 & 3 & 0 & 4 & 3 \\
\hline Med. preventiva & 0 & 0 & 1 & 0 & 0 & 1 & 1 & 1 \\
\hline Total & 3 & 5 & 8 & 10 & 10 & 4 & 21 & 19 \\
\hline
\end{tabular}

Tabela 4

Proporção entre Capital Simbólico e Capital Econômico

\begin{tabular}{lcccccc}
\hline & Clínicas & Psiquiátrica & Cirúrgicas & Mét. diag. & Med. prevent. & Total \\
\hline $\mathrm{CS}>\mathrm{CE}$ & 7 & 4 & 5 & 3 & 2 & 21 \\
$\mathrm{CS}<\mathrm{CE}$ & 5 & 1 & 9 & 4 & 0 & 19 \\
\hline Total & 12 & 5 & 14 & 7 & 2 & 40 \\
\hline
\end{tabular}

Nota. CS = capital simbólico; $\mathrm{CE}=$ capital econômico

Desta forma, foi feito um cotejo destas informações para cada um dos participantes, em que foram levados em consideração formas de expressão concreta ou enriquecida, fluxo de comunicação restrito ou expansivo, conteúdo limitado ou amplo e variado. No conteúdo, observou-se presença de temas recorrentes e repetitivos ou de interesses diversificados, necessidade de sinais de distinção ou não preocupação com aprovação externa.

As trocas simbólicas referem-se ao intercâmbio de experiências culturais e são produto da comunicação e do inter-relacionamento pessoal. Essas trocas são ambíguas porque seu sentido pode dar margem a interpretações variadas, mas podem ser vivenciadas porque existe correlação entre as estruturas mentais da pessoa e as estruturas objetivas do mundo externo sustentadas pelo coletivo. Existe uma correlação não direta entre capital econômico e capital simbólico, sendo o segundo fator determinante na escolha das possíveis práticas (Bourdieu,1996). Portanto, quanto à origem, é interessante saber, proporcionalmente, quem tem mais ou menos capital simbólico nos grupos de especialidades, como mostra a Tabela 4.

Como podemos notar, o grupo com maior capital simbólico é composto de 12 mulheres e nove homens, enquanto no grupo com menor capital simbólico 12 são homens e sete são mulheres. Observase que $64,3 \%$ dos cirurgiões (cinco homens e quatro mulheres) têm menor capital simbólico que econômico - estas especialidades têm como características o ritual técnico e a atividade em grupo. Já a maioria dos psiquiatras e os dois representantes da Medicina Preventiva têm maior capital simbólico do que econômico - ambas atividades são mais reflexivas e exercidas numa zona limítrofe entre a Medicina e outras áreas das ciências, especialmente as humanas.

\section{Bolsa de valores de especialidades}

Clavreul (1983) ressalta que o estudante de Medicina é submetido a um discurso que tem como finalidade desenvolver um saber absoluto e positivo. Tal discurso considera a doença, e não o homem, além de excluir a subjetividade, tanto de quem fala, como de quem escuta. O corpo é tido como local da doença e nunca sede do desejo. Assim, o médico é obrigado a pesquisar a causalidade da doença em fatos materiais.

Eu não consigo imaginar que a doença não seja palpável, como que a doença não seja mediadores químicos, entendeu? Legiões de DNA ... A filosofia, isso não existe, pra mim. Eu trabalho com uma coisa muito palpável, muito material. Eu tenho que tratar e curar, então eu não posso ficar me dando ao luxo de fazer filosofia. (homem, métodos diagnósticos)

A doença só existe concretamente, como a falta dela precisa ser visualmente constatada: $O$ meu doente ... eu chego, eu ponho a mão, eu apalpo, eu examino, eu vejo eletro, eu vejo o exame de sangue... (clínica).

Tudo fora dos limites do visível é vivido com angústia e desesperança. Só é possível fazer alguma coisa se a doença for delimitada fisicamente: Psiquiatria, quando eu passei a estudar no curso médico, me angustiava muito e as aulas que eu gostava mais eram psicossomática, que somatizava um pouquinho, trazia um pouquinho de organicismo (clínica).

As representações ligadas ao subjetivo são, em geral, negativas. Isso foi encontrado em 18 entrevistas.

Eu vou dizer para você o seguinte: o contato com o doente psiquiátrico para mim era uma coisa assustadora. Eu via no paciente, não um homem, homem no sentido que a gente tem, mas um homem totalmente deteriorado, sem espírito crítico, sim, um verdadeiro animal. (clínico)

Observa-se uma noção de homem racional, uma desconsideração com os afetos. A Psiquiatria, porque lida com estes doentes, é também vista com receio e distância. E só faz parte da Medicina, na medida em que as pesquisas avançam 
no sentido de justificar alterações psíquicas por alterações bioquímicas.

As representações encontradas confirmam esses aspectos de exclusão do subjetivo, como também de tudo que não seja salvar vidas:

Quem não gostava de estudar Medicina fazia Psiquiatria, assim como todo cara que era burro, ia fazer Ortopedia...Todo o bom ortopedista tinha que ter qualidade de ser burro e forte e o psiquiatra tem alguma coisa de louco, e não gosta de Medicina. Você vê que o estigma é desde a escola... aquele que não gosta de trabalhar, vai fazer Dermatologia, não vai ser chamado, aquelas coisas assim...(clínico)

As especialidades que cuidam de crianças e mulheres estão também entre as menos valorizadas. A tarefa médica valorizada é aquela, heróica, na qual a morte, a doença, são combatidas: Medicina é mais isso que en gostava, quer dizer, en queria fazer Cirurgia, achava bonito, bonito entubar um doente, sei lá, o cara estava chocado, você salva a vida dele (clínico).

É o cirurgião quem melhor incorpora esse papel de salvador. Ele é mais valorizado quanto mais pratica cirurgias de risco mortal. É figura admirada e invejada pelos colegas. Justamente por terem essa posição privilegiada, são muito criticados: Nós temos que conviver com aquilo que nós chamamos de 'prima donna'. Porque o cirurgião anda na pontinha do dedo, é um bailarino e você tem que ficar batendo palma (cirurgião-anestesista).

As especialidades cirúrgicas chamam muito a atenção, pois correspondem à fantasia heróica de tirar o 'mal', a doença. Doze entrevistados, fora os cirurgiões, pensaram em fazer cirurgia.

$\mathrm{Na}$ profissão médica, as mulheres ocupam, em geral, especialidades ligadas a crianças e mulheres. Aquelas selecionadas para profissões tidas como mais masculinas são mais rigorosamente selecionadas.

Primeiro eu precisava provar para todo mundo que eu era boa. Para ser aceita como residente, eu precisei ser a melhor interna, porque não queriam me abrir espaço para ser residente, porque eu ia ser uma exceção. E todo o mundo esperava que eu provasse ser boa, porque se eu não fosse boa, nunca mais ninguém ia ser cirurgiã no Brasil, eu acho. (cirurgiã)

Em Medicina, são consideradas profissões mais masculinas as que necessitam de mais ação, como as intervenções cirúrgicas e, especialmente, as que envolvem maior tensão, como cirurgia cardíaca ou neurológica. As mulheres ficam no lugar onde tradicionalmente há mais mulheres, como pediatria, ginecologia, obstetrícia, cirurgia plástica. Observamos esta questão em 11 entrevistas, das 19 feitas com o sexo feminino.

\section{História de vida}

Entre profissão e função desempenhada existem diferenças às vezes importantes, que cada indivíduo deve elaborar. É necessário fazer uma série de acertos como 'em quê?', 'onde?', 'como?' e 'com quem trabalhar?’. Enfim, que especialização escolher.
O indivíduo coloca na tarefa sua personalidade, sua memória, em confronto com as condições materiais provenientes da relação de trabalho, dos contextos social e histórico. Em relação ao significado do trabalho, existem dois componentes - o sujeito e o objeto. O conteúdo significativo em relação ao sujeito diz respeito a vários elementos que contribuem para a formação da imagem de si ou do narcisismo (Dejours, 1992).

O investimento narcísico abrange a evolução pessoal, os postos alcançados e o aperfeiçoamento diante da dificuldade prática da tarefa. Além deste investimento, existem outros relacionados com o material com o qual se lida. A natureza e o encadeamento destes símbolos dependem de cada um, de suas fantasias, do que cada um incorpora em sua atividade prática. Neste interjogo com a realidade, a intimidade, a história pessoal e o capital simbólico do sujeito estão intrinsecamente presentes em uma dialética específica e única. Seis representantes comentam terem seguido um professor ou um médico como modelo, diríamos idealizado, e todos uma figura masculina. A idealização é um mecanismo fortemente marcado pelo narcisismo, e alguns autores, como Klein (1952), interpretam seu significado como defensivo contra pulsões destrutivas: Eu conbeci um camarada que achava um modelo de pediatra do jeito assim que en gostaria de ser igual, só que ele trabalhava no Hospital do Câncer, e aí eu me aproximei bastante dele (clínico)

A questão que mais apareceu como fator responsável pela especialização foi a ansiedade desenvolvida no relacionamento com pacientes. Klein (1959) salienta que as simpatias e antipatias, além dos sintomas e atos falhos, expressam angústias primitivas relacionadas a fantasias inconscientes. Situações de empatia ou ansiedade foram mais relatadas pelas mulheres, tendo aparecido nove dentre 13 entrevistas. Hojat, Gonnella e Xu (1995) relatam que as médicas são mais propensas a valorizar os aspectos psicossociais dos cuidados médicos do que seus colegas masculinos: O professor de Neurologia era o caos ... assim, todos ótimos, era um tumulto, mas os doentes morrem! Morreu, né? Não tem satisfação, quer dizer, eu não achava aquilo muito atraente para mim (cirurgiã).

Percebe-se uma certa aflição, um desejo de se livrar o mais rápido possível de situações dolorosas, ou evitar circunstâncias pesarosas.

Eu sempre tive muito envolvimento, isso também foi uma outra coisa que me levou a me afastar, porque eu carregava o peso, principalmente de paciente com problemas mais graves. Quando eu estava na Pediatria, era de trazer comida de casa pra dar pra paciente. Eu sempre fui assim, e isso é extremamente desgastante. (homem, método diagnóstico)

Entre o homem e a organização prescrita para a realização do trabalho, existe um espaço de liberdade. Em determinadas tarefas é possível uma negociação para que possa ocorrer uma adaptação entre as necessidades e o desejo. O sofrimento só passaria a existir 
quando esse espaço de negociação ficasse bloqueado (Dejours \& cols., 1994).

Três representantes homens do grupo de Método Diagnóstico e duas mulheres, uma clínica e outra cirurgiã, comentaram que um dos motivos que os levaram à escolha da especialidade foram as condições de trabalho. Como a maioria das entrevistadas é casada e tem filhos, houve a necessidade de compatibilizar a vida privada e a profissional.

Os psiquiatras e os representantes da Medicina Preventiva são os que mais se assemelham em termos de capital simbólico. Fizeram cursos paralelos de Filosofia, Sociologia, interessam-se por Política, Literatura e Música, proporcionalmente mais que os médicos de outras especialidades. Todos dizem que optaram por especialidades mais abrangentes, mas o que têm em comum é o fato de trabalharem na fronteira da Medicina com áreas como Filosofia, Sociologia, Antropologia, Estatística e outras.

Não que a perspectiva biológica não tenha importância, é óbvio que tem importância. Mas são áreas que se complementam e a área que eu escolhi trabalhar me parece que é a área social. E a residência de Medicina Preventiva abria a possibilidade de você não se perder dentro da especialidade. (homem, Medicina Preventiva)

Os psiquiatras, da mesma forma que os integrantes da Medicina Preventiva, trazem uma preocupação com o ser humano em sofrimento em seus aspectos psíquicos e sociais. São eles que relatam sofrimento na relação com o paciente durante o curso médico.

Eu achava, eu gostava do contato com os pacientes, sempre me preocupava muito... acho que eu ficava muito constrangida com as coisas que a gente tinha que fazer com eles. O curso de Semiologia era um horror! Eu sabia que tinha dor, os pacientes tinham que suportar, porque a gente tinha que aprender de todo jeito aquelas coisas horrorosas do tipo: tem um sopro de tal jeito e aí fulano descreve e todo mundo bota o esteto no peito do pobre coitado... não era nada confortável. (mulher, psiquiatra)

Os mecanismos reparatórios ficam mais nítidos nesta fase de especialização. A reparação, termo cunhado por Klein (1959), diz respeito à capacidade de transformar em bons os danos praticados inconscientemente ao objeto amoroso. Esse processo é fundamental na formação de vínculos interpessoais e no desejo de criação.

Um vaso de plantas caiu sobre minha mão, acabou infectando e o médico drenou, mas na hora de drenar, ao invés de fazer neste sentido, que seria o correto, ele fez no sentido inverso. E o negócio que era uma coisa pequena, foi crescendo. Então, talvez esses fatos todos tenham feito com que eu me tenha dedicado mais à Pediatria. E talvez esse fato, e mais um acidente ocorrido com o meu irmão, que caiu da rede e morreu, talvez essas coisas é que me tenham orientado mais para a Pediatria. Foi marcante. (clínico)
Este comentário é de um imigrante. Seus pais fugiram da perseguição religiosa turca e, de sete filhos, só um sobreviveu. Nem sempre essas situações são conscientes e expressas em palavras. Mas nota-se uma evolução, um caminhar ligado à própria história.

Dejours (1992), sob a perspectiva da história de vida, chama de 'ressonância simbólica' ao arranjo criativo mobilizado diante da ambigüidade que aparece na transposição do teatro psíquico pessoal para o teatro do trabalho.

No $2^{\circ}$ ano, eu instrumentei tão direitinho que o residente falou: 'Você não quer dar uns pontinhos aqui numa ferida?' Na hora que eu peguei no porta-agulhas, eu peguei com tamanha naturalidade que ele disse: 'Você leva jeito!' Aí, eu também achei que eu levava jeito... Aliás, eu também costurava, quando eu era estudante, costurava todas as minhas roupas. É, eu era boa costureira, e quando me mandaram fechar a parede abdominal para mim foi banalidade, porque tem muito em cirurgia que é costura. (cirurgiã)

Este comentário é de uma representante da classe popular que começou a trabalhar aos 8 anos em diversas atividades manuais para ajudar os pais imigrantes árabes. Quando existe ressonância simbólica entre o teatro do trabalho e o teatro psíquico, o sujeito articula sua história, seu passado, com sua condição atual de modo criativo (Dejours, 1992).

Dejours e colaboradores (1994) assinalam também que as relações intersubjetivas entre os membros de uma mesma profissão criam defesas coletivas contra ansiedades comuns a todos. Forma-se uma ideologia defensiva constituída por representações comuns. No caso dos médicos, nas representações e no sistema de valores estão inseridas as noções de doença e doente. Este conjunto pode compor estratégias defensivas construídas e organizadas coletivamente e podem levar a uma suavização da percepção que os médicos têm da realidade que os faz sofrer.

\section{Considerações Finais}

As escolhas de profissão e especialidade médicas estão sujeitas a influências de caráter cultural, social e psíquico dos participantes e de suas familias, traduzidas pela origem, pelo capital simbólico e pelo capital econômico. Estas influências são incorporadas pelos representantes e continuam presentes nas práticas médicas, participando ativamente nas concepções, abordagens e conceitos da pessoa sobre o médico, a tarefa, a doença e o doente.

Observamos que a escolha profissional médica foi fruto de estratégias familiares de ascensão e manutenção de poder. A grande maioria da amostra, $82,5 \%$, tem pelo menos um dos avós imigrante e a ascensão social, pela via de obtenção de diploma universitário de prestígio, foi um dos caminhos escolhidos e valorizados. Notamos, também, que $55 \%$ da amostra são primogênitos.

Em geral, algumas particularidades culturais referentes a diferenças educacionais entre os sexos e que se refletem na escolha da especialidade estiveram presentes. A especialidade, por sua vez, resulta tanto da experiência individual com a descoberta de habilidades e 
interesses, como do capital simbólico da pessoa, herdado de sua familia de origem.

Os indivíduos apresentaram variações no que se refere à capacidade intrínseca para lidar com as ansiedades geradas pela tarefa médica. Os recursos internos para manejar e elaborar situações geradoras de tensão e ansiedade dependem da história pessoal de cada um e do capital simbólico próprio.

A hierarquia de valores na Medicina e suas diversas especialidades pode ser considerada como defesa coletiva contra ansiedades decorrentes da tarefa médica, do constante lidar com situações de impotência.

As diferentes atividades das tarefas médicas, apesar de envolverem um quantum de sofrimentos, fisico e psíquico, são gratificantes porque permitem atos e soluções criativos.

Consideramos importante a proposta de que, durante o curso de Medicina e Residência Médica, os temas destacados neste texto sejam abordados, na tentativa de assegurar a formação de profissionais que aliem o desenvolvimento técnico a uma prática médica mais integral, do ponto de vista do médico e do paciente.

\section{Referências}

Bardin, L. (1977). Análise de conteúdo. Lisboa: Edições 70.

Bohoslavsky, R. (1991). Orientação vocacional: A estratégia clínica. São Paulo: Martins Fontes.

Bourdieu, P. (1987). A economia das trocas simbólicas. São Paulo: Perspectiva.

Bourdieu, P. (1996). Razõos práticas: Sobre a teoria da ação. Campinas, SP: Papirus.
Bourdieu, P. \& Passeron, J. (1982). A reproducão: Elementos para uma teoria do sistema de ensino. Rio de Janeiro: Francisco Alves.

Clavreul, J. (1983). A ordem médica: Poder e impotência do discurso médico. São Paulo: Brasiliense.

Dejours, C. (1992). Uma nova visão do sofrimento humano nas organizações. Em J. -F. Chanlat (Org.), O indivíduo na organização: Dimensões esquecidas (pp. 149-173). São Paulo: Atlas.

Dejours, C., Abdoucheli, E. \& Jayet, C. (1994). Psicodinâmica do trabalho: Contribuiçoes da escola dejouriana à análise da relação prazer, sofrimento e trabalho. São Paulo: Atlas.

Hojat, M., Gonnella,J. S. \& Xu, G. (1995). Gender comparisons of young physicians' perceptions of their medical education, professional life and practice: A followup study of Jefferson Medical College Graduates. Academic Medicine, 70, 305312.

Klein, M. (1975). Identificação e trabalho de reparação. Em J. Riviere (Org.), Amor, ódio e reparação (pp. 95-97). Rio de Janeiro: Imago. (Original publicado em 1959)

Klein, M. (1982). Algumas conclusões teóricas sobre a vida emocional do bebê. Em P. Heimann, S. Isaacs, \& J. Riviere (Orgs.), Os progressos da Psicanálise (pp. 216-255). Rio de Janeiro: Zahar. (Original publicado em 1952)

Patton, M. G. (1990). Qualitative evaluation and research methods. California: Sage.

Rodrigues, A. M. (1978). Operário, operária: Estudo exploratório sobre o operariado industrial da Grande São Paulo. São Paulo: Símbolo.

Rodrigues, A. M. (1981). Dinâmica grupal e indivíduo no sistema de distribuição de privilégios na família. Cadernos de Pesquisa, São Paulo, 37, 52-59.

Sobre as autoras

Maria Luiza de Mattos Fiore é Médica Psiquiatra, Doutora em Medicina pela Universidade Federal de São Paulo (Escola Paulista de Medicina), Departamento de Psiquiatria e Psicologia Médica, Disciplina de Psicoterapia e Psicodinâmica.

Latife Yazigi é Psicóloga, Professora Titular na Universidade Federal de São Paulo (Escola Paulista de Medicina), Departamento de Psiquiatria e Psicologia Médica, Disciplina de Psicoterapia e Psicodinâmica. Departamento de Psiquiatria e Psicologia Médica, Disciplina de Psicoterapia e Psicodinâmica. É Pesquisadora CNPq 1A. 